Servicio de publicaciones y difusión científica (SPDC), Universidad de Las Palmas de Gran Canaria, Parque CientíficoTecnológico, Edificio Polivalente II, C/ Practicante Ignacio Rodríguez, s/n Campus Universitario de Tafira 35017 - Las

Palmas de Gran Canaria, Spain.

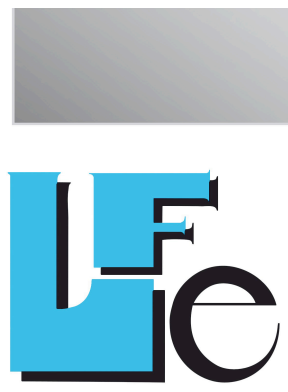

Revista de Lenguas para Fines Específicos

\section{Revista de lenguas} para fines específicos

\author{
elSSN: $2340-8561$
}

Journal information, indexing and abstracting details, archives, and instructions for submissions:

https://ojsspdc.ulpgc.es/ojs/index.php/LFE/index

\section{Introduction: A focus on foreign language learners' success}

\section{Patricia Arnaiz Castro}

Universidad de Las Palmas de Gran Canaria, Departamento de Didácticas Especiales. Facultad de Ciencias de la Educación. C/ Pérez del Toro, s/n 35004 Las Palmas de Gran Canaria (Spain).

Article first published online: 27 July 2015.

Article published online with DOI added: 5 April 2016 


\title{
INTRODUCTION: A FOCUS ON FOREIGN LANGUAGE LEARNERS' SUCCESS
}

\author{
Patricia Arnaiz Castro ${ }^{1}$ \\ Universidad de Las Palmas de Gran Canaria
}

The more and more prominent role of English in the Spanish Education system has brought to the foreground the relevance of research in the teaching and learning of English as a foreign language (FL). At no other time in the history of Spanish education have teachers of English been so knowledgeable about pedagogy, learning theories and curriculum planning or had so many resources at their disposal. Yet, and despite considerable progress made over the years, students rarely achieve high levels of proficiency in English at the end of a course of study. Why?

This monograph alone does not intend to answer the question. Neither does it aspire to cover the entire range of variables that directly or indirectly have an impact on FL teaching and learning. The purpose of this monograph is to be the first of a series which provides state-of-the-art overviews of what is already known and of what requires further study in a wide range of fields to which foreign language teaching and learning can be applied. To this end, the papers published within this volume cover the research domains of Information and Communication Technology -in connection with students' perceptions-, Content and Language Integrated Learning -in relation with students' anxiety levels and attitudes-, needs analysis, interlanguage and textbooks and the intercultural communicative competence. The

1 Corresponding author - Universidad de Las Palmas de Gran Canaria, Departamento de Didácticas Especiales. Facultad de Ciencias de la Educación. C/ Pérez del Toro, s/n 35004 Las Palmas de Gran Canaria (Spain).

Email: patricia.arnaiz@ulpgc.es 
evidence provided by the five selected papers about the situation in Spanish institutions will map out the current interdisciplinary findings on a specific common problem facing educationalists: how to promote better English learning. Two features make the volume especially appealing: the presence of all levels of education and the incorporation of an often neglected group of learners: adult learners of English in the Escuela Oficial de Idiomas (Official Language School).

\section{ICT use and perceived effectiveness in an adult EFL learning context, by Stephen Hughes and Bojana Tulimirovic}

ICT is a valuable tool for enhancing both teaching and learning. For teachers, on the one hand, it is a professional resource and a mode of classroom delivery, while for students, ICT provides opportunities to communicate more effectively and to develop the different language skills. There is general consensus in the field as regards the roles that ICTs can fulfil. They increase motivation to learn languages, enabling language learning across institutions and outside formal educational contexts; apart from offering opportunities for meaningful practice of language in authentic contexts. But how these tools actually support both the acquisition of mastery of that foreign language and classroom delivery needs further investigation. That is precisely the focus of Hughes and Tulimirovic's paper. With a mixed-method study that used both quantitative and qualitative data, the authors analyse the views of teachers and students towards their use of digital resources and their perceived effectiveness.

The range of technologies available for use in language learning and teaching has become very diverse, but making effective use of them requires an understanding of their potential to meet different objectives and, consequently, to decide which of these objectives will be pursued. In Hughes and Tulimirovic's study, a group of 67 adult Spanish learners of different proficiency levels were asked to report the frequency of use of ICTs for developing and practising different skills and competences, and to express their opinions on the usefulness of ICTs and whether these technologies help them improve. In addition, they were asked about the specific technological tools they use and to specify for which skill/competence. Four teachers, on the other hand, answered a semi-structured interview about the usefulness of ICTs in their particular language learning context, their preferences for certain activity types, and the difficulties they had come across.

This study is relevant not so much for measuring "how much" and "how often" and for collecting information about "what type" but for providing valuable evidence for the need to explore the procedure to find a balance between the different skills and competences improved with ICT support. It is absolutely unacceptable nowadays 
that students do not benefit from ICTs to improve their oral expression and oral interaction, as the results in Hughes and Tulimirovic's study show. This study is also important for contributing to a line of inquiry that recognises that, in order to maximise the potential of ICT, both teachers and learners need training and guidance.

\section{Affective Variables in Second Language Acquisition and their Effect on the Spanish Academic Context, by Alba Muñoz and José Luis Ortega}

Whilst the content and language integrated learning (CLIL) or 'bilingual' learning in state schools is a topic of major concern in Spain, there is a surprising dearth of research work focusing on the effects of its implementation. Muñoz and Ortega's paper is intended to address this deficit.

Over the last two decades there has been a rapid growth in Spanish schools and high schools offering CLIL programmes. Lightbown and Spada (2006) referred to content-based programmes as the "two for one approach" because students in these programs learn subject matter such as Maths or Science in the target language -English in the case of Spain-, thus substantially increasing the amount of contact time with the English language. Although it is true that evidence from research in Europe is a key step in establishing an evidence-base for CLIL, it is also true that only data pertaining to the Spanish context will serve as true orientation for teachers' decision-making and performance. The particular characteristics and profiles of teachers and students in Spain have very little in common with those of students and teachers in countries like France or Sweden.

The paper by Muñoz and Ortega examines two central aspects. The first one is the difference in anxiety levels, attitude and motivation among bilingual and nonbilingual groups in a state high-school and how the atmosphere in both contexts changes. The second issue is related to the teachers' performance in class and its effect on students' feelings of anxiety, motivation and attitudes towards their language classes. The findings, obtained from a quantitative and qualitative analysis, will reassure educators about the benefits of CLIL and at the same time provoke valuable discussion about the next steps to be taken in creating more effective forms of CLIL. In addition, the data presented will shed light on the impact that certain teachers' behaviour can have on students' learning process. The fact that this research includes data collected from the observation of teaching sessions makes it particularly relevant. Classroom observation is a pivotal element of teacher professional development but, unfortunately, teachers are quite often reluctant to engage in research that requires having a researcher in class observing their 
performance and registering their behaviour (Lasagabaster \& Sierra, 2011). They characteristics of the situation are certainly intimidating and threatening.

\section{Foreign language learning needs in higher education: Reasons for convergence and accountability, by Ana Bocanegra}

Bocanegra contributed the third study, which discusses the definition and development of needs analysis and its application in teaching English as a foreign language in the university context. Needs analysis plays a vital role in the process of designing and carrying out any language course, and its centrality has been acknowledged by several scholars and authors. In her paper, the author brings together descriptions of distinctive contributions to research into needs analysis in higher education and presents the main models and the methods of data collection in carrying out a needs analysis. In addition, the writer gives a critical evaluation of some disadvantages of the early types of needs analysis and the improvements on the present types. Finally, the author highlights the relevance in today's society of being aware of the fact that different types of needs analyses are not exclusive but complementary and that each of them provides a piece to complete the jigsaw.

Generally, reviews of research are the underappreciated workhorses of academic publication. Yet, they play a significant part in the advancement of knowledge, as they bring out milestones of progress in a particular field of study. Carefully elaborated and well-structured reviews like Bocanegra's, orient researchers in the identification of priorities for future study directions.

Out of the wide scope of results obtained throughout the history of needs analysis research, there is one that seems of particular interest: studies conducted both in the Spanish context and in other European contexts underline the fact that not enough attention is paid to the speaking skill in higher education. The results obtained in the research done by Hughes and Tulimirovic with adult learners point in the same direction: the speaking skill was the skill least practiced by students when using ICTs. Inevitably, these data invite for reflection in a country like Spain where students lag behind in the mastery of English communicative competence.

\section{El desarrollo de la competencia comunicativa intercultural a través del aprendizaje cultural en los libros de texto, by Antonio R. Raigón- Rodríguez}

The role of culture in foreign and second language teaching has long been discussed in professional literature and views on why language teachers should integrate culture in their classroom activities, what and how they should teach have varied 
considerably over the decades. What most scholars agree on is that language and culture are connected and cannot be detached from one another, even though they differ on how to determine what cultural content needs to be studied. Some experts have even suggested treating culture as another language skill (Tomalin, 2008).

Nowadays, foreign language textbooks have become the major channels for culture introduction. This paper is concerned with the inseparability of culture and language in foreign language textbooks. Specifically, it investigates whether, and to what extent, three foreign language textbooks, edited by the three most widely used publishers in Spain, namely Cambridge University Press, Macmillan and Oxford University Pres, can contribute to promoting university students' acquisition of intercultural communicative competence. After presenting various definitions and interpretations of the term culture, Raigón situates his approach within an existing body of research that has conceptualised culture following the model proposed by Paige et al (1999) and Lee (2009). The results indicate that three textbooks show a strong preference for the transmission of knowledge corresponding to the "culturegeneral" domain such as literature, music or cinema, while neglecting knowledge related to the culture-specific domain such as justice or self-improvement. Two main problems are highlighted by the author, first the restriction in the implementation of language skills in connection with cultural aspects and, secondly, the few opportunities given to students for reflexive engagement with cultural information and representation. The task of promoting global cultural consciousness in the foreign language classroom cannot be correctly accomplished unless it is through all the language skills and through critical reflection. Once again, the data point to a lost opportunity for the speaking skill enhancement.

Although this paper offers the analysis of only three textbooks, it still constitutes a valuable contribution to the literature on the development of intercultural competence in and through foreign language education.

\section{Tense and agreement markers in the interlanguage of Spanish learners of English, by José Antonio Medina}

The last paper adds to an already impressive body of work that investigates the acquisition of verbal morphemes by Spanish students learning English. The particular relevance of this study lies in the use of a statistically significant sample from a specific population and in the ranges of ages and levels included. The approach selected to analyse the FL learning process of Spanish speakers follows Selinker's idea of an Interlanguage system. The term interlanguage refers to the intermediate status of the foreign language learner's system between his/her mother tongue and the target language (Selinker, 1972). As Han and Tarone (2014: 
vii) admit, "few works in the field of second language acquisition (SLA) can endure multiple reads, but Selinker's (1972) "Interlanguage" is a clear exception". According to the Interlanguage theory, an active and independent learning mind always makes its own generalisations upon dealing with a new language, and the errors made by the learner are considered in fact "correct" by the rules of an "interlanguage" made up by the learner as a temporary substitute. In this light, it is inevitable that learners should make mistakes in the process of foreign language learning and attempting to make learners see "errors" as the downside of language sessions has the effect of destroying their capacity to organise their own progress. Nevertheless, teachers, who very often cannot escape from a preoccupation with learners' errors, question why students go on making the same mistakes even when such mistakes have been repeatedly pointed out to them. In this respect, the main aim of Medina's study is to analyse the functional category of Inflection with the intention of establishing the success of the learning process. The focus was placed on the grammatical morphemes marking past tense (-ed) and agreement (-s), as well as the verb be. The results show a predominant omission for the agreement morpheme $-s$ in the three groups analysed (primary education, secondary education and upper sixth form). On the other hand, the bound morpheme -ed and the free morpheme be present the highest percentage of correct use. Comprehensive studies like this are of utmost importance in the language learning field. However, an issue that remains unsolved is the successful transmission of part of this information to teachers. In fact one of the major problems in foreign language education is the lack of teachers' understanding of foreign language acquisition theories.

\section{Acknowledgements}

I owe a debt of gratitude to PhD. Francisco Alonso Almeida, editor-in-chief of LFE, whose guidance, assistance and advice have been vital. I am sincerely grateful to him for generously sharing his knowledge and experience, as well as giving up his time.

\section{About the author}

Patricia Arnaiz Castro is Senior Lecturer of English as a Foreign Language for future primary teachers and Foreign Language Teaching Methods for future secondary teachers (University of Las Palmas de Gran Canaria). Her research interests are 
focused on students' output and on the role affective variables such as anxiety and self-concept can have in the foreign language learning process.

\section{References}

Han, Z. and Tarone, E. (Eds.) (2014). Interlanguage. Forty years later. Language Learning \& Language Teaching, 39. Amsterdam, The Netherlands: John Benjamins Publishing Company. DOI: 10.1075/IIlt.39.

Lasagabaster, D. and Sierra, J. M. (2011). Classroom observation: desirable conditions established by teachers. European Journal of Teacher Education 34(4), 449-463. DOI:10.1080/02619768.2011.587113

Lee, K. (2009). Treating culture: What 11 high school EFL conversation textbooks in South Korea do. English Teaching: Practice and Critique, 8(1), 76-96.

Lightbown and Spada (2006) (3rd ed). How Languages are Learned. Oxford: Oxford University Press.

Paige, R., Jorstad, J., Paulson, L., Klein, F., y Colby, J. (1999). Culture learning in language education: A review of the literature. En R. Paige, D. Lange, y Y.Yershova (Eds.), Culture as the core: Integrating culture into the language curriculum. Minneapolis, MN: The Center for Advanced Research on Language Acquisition, University of Minnesota.

Selinker, L. (1972). Interlanguage. International Review of Applied Linguistics in Language Teaching 10(1-4), 209-232.

Tomalin, B. (2008). Making culture happen in the English language classroom. Teaching English. BBC Britsh Council. (Available at https://www.teachingenglish.org.uk/article/ makingculture-happen-english-language-classroom. Accessed 26th June 2015). 